\title{
Ambiente virtual para tratamento de ansiedade oriunda de traumas usando Dessensibilização e Reprocessamento por Movimentos Oculares
}

\author{
Bruna Cons \\ Pós-graduação em Ciências Computacionais \\ UERJ - Rio de Janeiro \\ brunacons94@gmail.com
}

\begin{abstract}
The aim of this work is to present a 3-D virtual immersive environment, integrating Artificial Intelligence techniques to support the treatment of anxiety using the EMDR strategies to desensitize past traumatic events.
\end{abstract}

\section{KEYWORDS}

Artificial Intelligence, Subjective Units of Distress Scale

\section{Introdução}

Este trabalho é uma proposta de dissertação de mestrado, associada ao tema "VR/AR/MR systems, frameworks and toolkits" do SVR2021.

As tecnologias computacionais, especialmente a Inteligência Artificial (IA) e a Realidade Virtual (RV), aplicadas na área da saúde abrem novas possibilidades para pesquisas e tratamento de diferentes deficiências.

$\mathrm{Na}$ área neuropsiquiátrica, a Dessensibilização e Reprocessamento do Movimento Ocular (EMDR) é uma técnica que considera que o movimento ocular horizontal, repetitivo, guiado pela assistência terapêutica, auxilia a reduzir os sentimentos ruins associados a memórias traumáticas [1]. O EMDR tem sido aplicado no tratamento de dessensibilização de memórias dolorosas, reduzindo os sintomas de ansiedade. Em português não foram encontrados trabalhos que forneçam suporte mais automatizado para o terapeuta explorar a técnica e ao mesmo tempo, motivar o paciente a utilizá-la com maior engajamento

Apoiado por uma revisão da literatura, este artigo apresenta a proposta de um sistema que integra Multiagentes, Lógica Fuzzy e Realidade Virtual para dar assistência à técnica EMDR para dessensibilizar eventos passados de pessoas com sintomas associados ao estresse pós-traumático.

O sistema apresenta um terapeuta virtual que interage com o usuário, coletando informações sobre a sua memória traumática, considerando o nível de ansiedade atual e os batimentos cardíacos. A integração desses dois dados em um sistema Fuzzy, irá controlar o nível de intensidade dos estímulos no ambiente de Realidade Virtual, que a partir desse dado pode modificar a velocidade do exercício a ser realizado com os olhos. O uso da lógica Fuzzy é ideal para este tipo de avaliação, por permitir realizar uma ponderação de valores difusos e gerando um resultado equilibrado.

\author{
Rosa Maria E. Moreira da Costa \\ Pós-graduação em Ciências Computacionais \\ UERJ - Rio de Janeiro \\ rcosta@ime.uerj.br
}

Consideramos que a maior contribuição deste trabalho para a área da saúde encontra-se na integração destas tecnologias, de forma inovadora, em um ambiente que proporcionará o controle da velocidade do exercício de EMDR de forma mais precisa, de acordo com o nível de ansiedade do paciente.

\section{Revisão Teórica}

\subsection{EMDR}

O EMDR é uma técnica de terapia relativamente recente, sendo ainda pouco difundida no Brasil. A técnica considera que o movimento repetitivo e horizontal dos olhos, seguindo com o olhar algum objeto, com o apoio de assistência terapêutica diminui sentimentos ruins associados a memórias estressantes. Nesse caso, o cérebro pode trabalhar a memória de forma mais lógica, diluindo sintomas de ansiedade. Quando a pessoa acessa uma memória traumática com menos emoções ruins associadas a ela, pode se desvincular aos poucos, das consequências dos traumas em seu cotidiano. Isso ocorre por meio da estimulação de novas redes neurais, que representam experiências novas sendo associadas às redes já existentes. Durante a sessão, o terapeuta precisa interagir verbalmente com o paciente, que por sua vez, deve fornecer uma classificação para o seu nível de ansiedade a cada fase - a escala SUDS (Subjective Units of Distress Scale) [2].

\subsection{Lógica Fuzzy}

Ao contrário da lógica Booleana que só admite valores booleanos, ou seja, 0 ou 1 , falso ou verdadeiro, a lógica difusa, ou Fuzzy, engloba os valores existentes entre o 0 e o 1 . São valores nebulosos que permitem uma abrangência maior de opções, sendo úteis em problemas mais complexos, que exigem uma análise qualitativa e devem admitir maior nível de incerteza nos resultados [3]. Sistemas Fuzzy podem combinar dados de diferentes origens, para gerar resultados, que podem contribuir na tomada de decisões. No caso desta proposta, iremos combinar dados fisiológicos, tal como os batimentos cardíacos, com a resposta do paciente sobre o nível de ansiedade que ele está sentindo - usando a escala SUDS, para determinar um nível de ansiedade que por sua vez, controla a velocidade do estimulo a ser seguido pelo olhar do paciente.

\subsection{Agentes}

Agentes de software são entidades que realizam tarefas específicas, podendo ter características como autonomia e inteligência. A eficiência dos agentes irá depender das 
especificações de cada capacidade e como elas interagem entre si, visto que agentes são agrupados em Sistemas Multiagentes (MAS).

\section{Trabalhos Correlatos}

Visando identificar como a Inteligência Artificial (IA) tem sido utilizada em aplicações de Realidade Virtual na área médica, foi realizada uma revisão bibliográfica que após filtragens, encontrou 31 artigos considerando os anos de 2010 a 2018. A análise dos trabalhos mostrou que o uso de agentes é predominante nos artigos encontrados, seguido pelas Redes Neurais e Lógica Fuzzy. Observou-se que grande parte dos trabalhos aplicados na área da psicoterapia explorou a técnica de Multiagentes. Esta parece ser uma tendência em aplicativos que precisam monitorar a evolução do desempenho de pacientes.

\section{Solução Proposta}

O sistema EM-VR apresenta um terapeuta virtual masculino que interage com o usuário. $\mathrm{O}$ terapeuta real fornecerá todo o apoio em relação a colocação do equipamento de visualização e acompanhamento da sessão. O sistema indaga o paciente sobre seu nível de ansiedade, que é combinado com os batimentos cardíacos. A integração desses dados é realizada por um módulo Fuzzy, que fornecerá resultados para controlar o nível de intensidade dos estímulos apresentados no ambiente de Realidade Virtual, para controlar o movimento a ser realizado com os olhos (Figura 1).

\begin{tabular}{|c|c|c|c|c|c|}
\cline { 3 - 6 } & & \multicolumn{4}{|c|}{ Janela de Tolerância } \\
\hline & & ABALXo & DENTRo & $\begin{array}{c}\text { LIMIAR } \\
\text { SUPERIOR }\end{array}$ & ACIMA \\
\hline \multirow{2}{*}{$心$} & BAIXA & Média & Baixa & Média & Alta \\
\cline { 2 - 6 } & MÉDIA & Média & Baixa & Média & Alta \\
\cline { 2 - 6 } & ALTA & Alta & Média & Alta & Alta \\
\hline
\end{tabular}

Figura 1: Classificação do nível de ansiedade combinando o SUDS com os níveis de batimentos cardíacos, gerando a indicação de velocidade dos estímulos visuais.

Foi implementado um protótipo usando a ferramenta UNITY para que especialistas avaliassem o sistema, considerando várias dimensões. O EM-VR (Figura 2) é para ser utilizado no smartphone, ampliando as possibilidades de uso.

\section{Resultados Preliminares}

Após a aprovação do projeto pelo comitê de ética, um vídeo do EM-VR foi disponibilizado para 8 profissionais das áreas de psicologia e psiquiatria, para avaliar: o conteúdo, a interface e a usabilidade. Os participantes responderam a três questionários relativos às três dimensões avaliadas. O terceiro foi o SUS (System Usability Scale) [2]. O resultado do SUS foi de 71,56 e segundo a metodologia, classifica o sistema como bom, porém apenas um pouco acima da classificação média, que tem limite superior de 68 . A Figura 3 apresenta o resultado do questionário sobre a Interface.

Esse resultado corroborou as expectativas dos autores, que agora irão finalizar o sistema na estrutura de Multiagentes. Os agentes propostos são: Agente de Cenografia, Analisador e
Controlador. O Agente de Cenografia gera e mantém a cena no ambiente de RV, exibindo a sala com o terapeuta e a bola em movimento, usada pelo Agente Controlador. Este agente garante que o sistema seguirá a ordem de uma sessão EMDR, terminando ou pausando, se necessário, controlando o andamento da sessão. O Agente Analisador é responsável por receber as informações de frequência cardíaca do usuário e respostas sobre o nível de sua ansiedade, combinando os dois no módulo Fuzzy e enviando o resultado para o Agente de Cenografia. A modelagem EM-VR utilizou uma estrutura orientada ao objetivo, denominada $i$ * (i-star) [4], que identifica os atores (usuários e agentes), as tarefas e os recursos necessários para processar as tarefas.

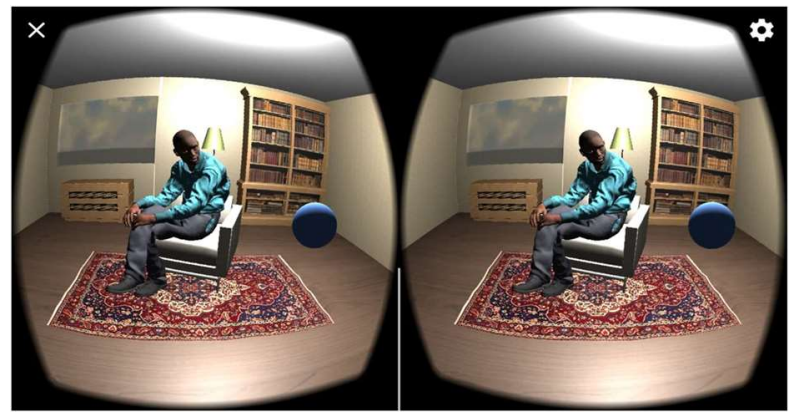

Figura 2: Imagem do EM-VR

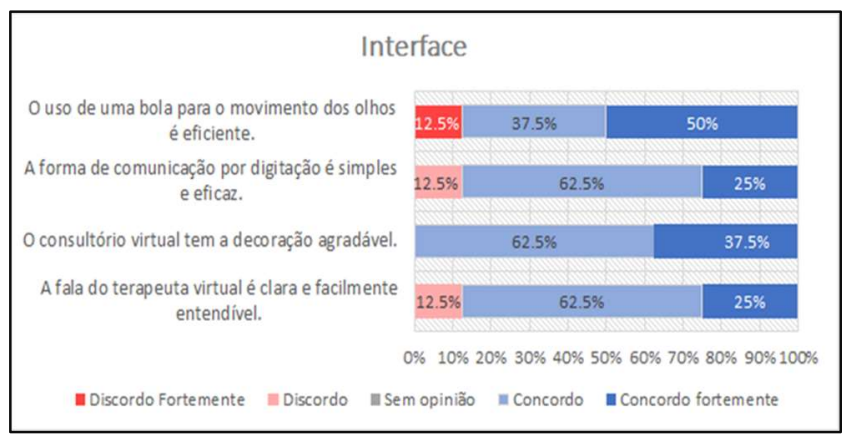

Figura 3: Resultado da avaliação da Interface

\section{Conclusões}

A integração da técnica de Multiagentes com a Lógica Fuzzy possibilitará a criação de um ambiente mais autônomo e motivador para o paciente, uma vez que ele pode ficar focado em realizar o movimento dos olhos, sem perceber estímulos externos, além dos fornecidos pelo terapeuta real.

\section{REFERENCES}

[1] Francine Shapiro. 1989. Eye movement desensitization: A new treatment for posttraumatic stress disorder. Journal of behavior therapy and experimental psychiatry, 20, 3, 211-217. DOI: https:// doi.org/10.1016/0005-7916(89)90025-6

[2] John Brooke et al. 1996. SUS-A quick and dirty usability scale. Usability evaluation in industry, 189, 194.

[3] Lofti Zadeh. 1965. Fuzzy sets. Information and control, 8, 3, 338-353. DOI: https://doi.org/10.1142/9789814261302_0021

[4] Eric Yu. 2011, Chapter 2: Modeling Strategic Relationships for Process Reengineering, Social Modeling Engineering, editors. Yu E, Giorgini P, Maiden N, Milopoulos, J, Toronto, 11-154 